\title{
Skeletal muscle loss after total gastrectomy, exacerbated by adjuvant chemotherapy
}

\author{
Yusuke Yamaoka $\cdot$ Kazumasa Fujitani · \\ Toshimasa Tsujinaka $\cdot$ Kazuyoshi Yamamoto • \\ Motohiro Hirao $•$ Mitsugu Sekimoto
}

Received: 7 November 2013/ Accepted: 28 February 2014/Published online: 9 April 2014

(C) The International Gastric Cancer Association and The Japanese Gastric Cancer Association 2014

\begin{abstract}
Background Skeletal muscle loss is associated with physical disability, nosocomial infections, postoperative complications, and decreased survival. Preventing the loss of skeletal muscle mass after gastrectomy may lead to improved outcomes. The aims of this study were to assess changes in skeletal muscle mass after total gastrectomy (TG) and to clarify the clinical factors affecting significant loss of skeletal muscle after TG.

Patients and methods One hundred and two patients undergoing TG for primary gastric cancer underwent abdominal computed tomography before and 1 year after TG to precisely quantify postoperative changes in skeletal muscle and adipose tissue. Univariate and multivariate logistic regression analyses identified clinical factors contributing to significant loss of skeletal muscle after TG.

Results At 1 year after TG, the mass of both skeletal muscle and adipose tissue was reduced by $6.20 \pm 6.80$ and $65.8 \pm 36.1 \%$ of the preoperative values, respectively,
\end{abstract}

Y. Yamaoka $\cdot$ K. Yamamoto $\cdot$ M. Hirao - M. Sekimoto Department of Surgery, National Hospital Organization Osaka National Hospital, Osaka, Japan

e-mail: yamaoka.yusuke@gmail.com

\section{K. Fujitani $(\square)$}

Department of Surgery, Osaka Prefectural General Medical Center, 3-1-56 Bandaihigashi, Sumiyoshi-ku, Osaka 558-8558, Japan

e-mail: fujitani@gh.opho.jp

T. Tsujinaka

Department of Surgery, Kaizuka City Hospital, Kaizuka, Japan and 26 patients $(25.5 \%)$ showed a significant loss of skeletal muscle of more than $10 \%$. Adjuvant chemotherapy with S-1 for $\geq 6$ months (hazard ratio $26.61,95 \%$ confidence interval, 3.487-203.1) was identified as the single independent risk factor for a significant loss of skeletal muscle.

Conclusions Skeletal muscle loss was exacerbated by extended adjuvant chemotherapy after TG. Further research should identify appropriate nutritional interventions for maintaining skeletal muscle mass and leading to improved outcomes.

Keywords Total gastrectomy - Skeletal muscle loss · Adjuvant chemotherapy $\cdot$ S-1 $\cdot$ Risk factor

\section{Introduction}

Skeletal muscle loss is associated with aging and physical disability [1] and is also caused by chronic disease and malignancy [2]. It leads to nosocomial infections [3], postoperative complications [4-7], increased length of hospital stay [7, 8], and decreased survival in nonmalignant as well as malignant populations [9-12].

Body weight loss is common in patients with gastric cancer undergoing total gastrectomy (TG). Although the main postoperative change in body composition after TG is a loss of fat mass, various degrees of skeletal muscle mass reduction have been demonstrated [13-15]. Preventing the loss of skeletal muscle mass after TG may lead to improved outcomes.

This retrospective analysis was conducted to reveal changes in body composition, including skeletal muscle mass, that occur after TG, and to clarify clinical factors affecting significant loss of skeletal muscle. 


\section{Patients and methods}

Study population

We retrospectively reviewed the records of 218 patients who had undergone TG for primary gastric cancer between January 1, 2006 and December 31, 2011 at Osaka National Hospital. Patients with preoperative chemotherapy $(n=47)$, any incurable factors $(n=37)$, relapse within 1 year after surgery $(n=24)$, or concurrent malignancy $(n=8)$ were excluded from this analysis. The remaining 102 patients served as our study cohort. All the patients underwent open TG with Roux-en-Y reconstruction, and those with pathological stage II/III disease according to the Japanese classification of gastric carcinoma [16] received postoperative adjuvant chemotherapy with the oral 5-fluorouracil (5-FU) agent $\mathrm{S}-1$ for 1 year if tolerated.

Data were collected on the following variables: age, sex, preoperative body mass index (BMI), the presence of diabetes mellitus (DM) requiring medications or insulin therapy, surgical procedures (degree of lymph node dissection and presence of combined splenectomy and/or distal pancreatectomy), postoperative complications according to the Clavien-Dindo classification [17], pathological stage, and compliance with adjuvant chemotherapy.

\section{CT image analysis of body composition}

Abdominal computed tomography (CT) images were acquired both preoperatively and at 1 year (median, 1.0 year; range, $0.90-1.10$ years) postoperatively in all patients for the evaluation of tumor staging and diagnosis of recurrent disease. CT imaging also provided a means of precisely quantifying body composition [18]. CT images at the third lumbar vertebra (L3) were assessed for each patient. Images were analyzed with Volume Analyzer SYNAPSE VINCENT (Fujifilm, Tokyo, Japan), which enabled the demarcation of specific tissues using Hounsfield units (HUs). Skeletal muscle was identified and quantified by HU thresholds of -29 to 150 [19]. The muscles in the L3 region are the psoas, erector spinae, quadratus lumborum, transversus abdominis, external and internal obliques, and rectus abdominis. The following $\mathrm{HU}$ thresholds were used for adipose tissues: -190 to -30 for subcutaneous and intramuscular adipose tissue [20], and -150 to -50 for visceral adipose tissue [21]. Tissue boundaries were manually corrected if needed. Tissue cross-sectional area $\left(\mathrm{cm}^{2}\right)$ was calculated automatically by summing tissue pixels and multiplying by pixel surface area, and was subsequently normalized for stature $\left(\mathrm{m}^{2}\right)$ and reported as lumbar skeletal muscle index (SMI) $\left(\mathrm{cm}^{2} / \mathrm{m}^{2}\right)$ and adipose tissue index (ATI) $\left(\mathrm{cm}^{2} / \mathrm{m}^{2}\right)$ [18]. All CT images were analyzed by a single trained specialist.
Postoperative changes in skeletal muscle and adipose tissue were evaluated.

Statistical analysis

SAS statistical software version 5.0 (SAS Institute, Cary, NC, USA) was used for all statistical analyses, and a $P$ value $<0.05$ was considered significant. Data are presented as mean $\pm \mathrm{SD}$. The two-sample independent $t$ test and $\chi^{2}$ test were employed to evaluate differences in continuous and categorical variables, respectively. Univariate and multivariate logistic regression analyses were used to identify clinical risk factors for a significant loss of skeletal muscle mass after TG.

\section{Results}

Patient characteristics

The clinical characteristics of the 102 patients are listed in Table 1. No patients showed recurrence at the evaluation of body composition. The study population consisted of 71 men and 31 women with a mean age of $63.9 \pm 10.5$ years.

Table 1 Patient characteristics $(n=102)$

\begin{tabular}{ll}
\hline Characteristic & $n=102$ \\
\hline Age (years) & $63.9 \pm 10.5$ \\
Sex & \\
Male & 71 \\
Female & 31 \\
Preoperative body mass index $\left(\mathrm{kg} / \mathrm{m}^{2}\right)$ & $22.6 \pm 3.25$ \\
Diabetes mellitus & \\
Present & 9 \\
Absent & 93 \\
Surgical procedure & \\
Lymphadenectomy D1+/D2 & $10 / 92$ \\
Splenectomy/distal pancreatectomy & $16 / 2$ \\
Postoperative complication & 22 \\
Anastomotic leakage & 3 \\
Pancreatic fistula & 5 \\
Intraabdominal abscess & 7 \\
Ileus & 1 \\
Wound dehiscence & 4 \\
Pneumonia & 2 \\
Clavien-Dindo classification of postoperative complications \\
Grade II/III/IV & $14 / 7 / 1$ \\
Pathological stage I/II/III & $50 / 28 / 24$ \\
Adjuvant chemotherapy & \\
None or $<6$ months & 64 \\
$\geq 6$ months & 38 \\
\hline
\end{tabular}



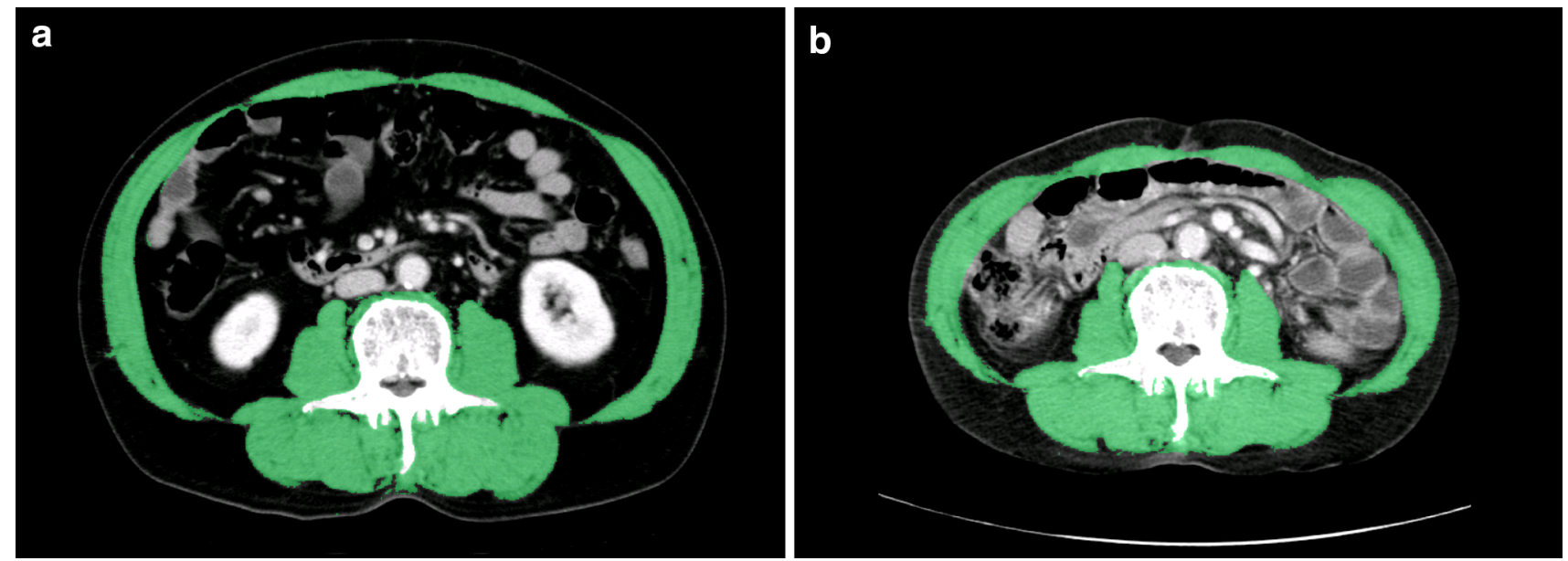

Fig. 1 Typical transverse computed tomography (CT) images at L3 show postoperative changes in skeletal muscle (green). The preoperative total muscle area of $143 \mathrm{~cm}^{2}$ (a) decreased to $122 \mathrm{~cm}^{2}$ at 1 year after surgery (b)
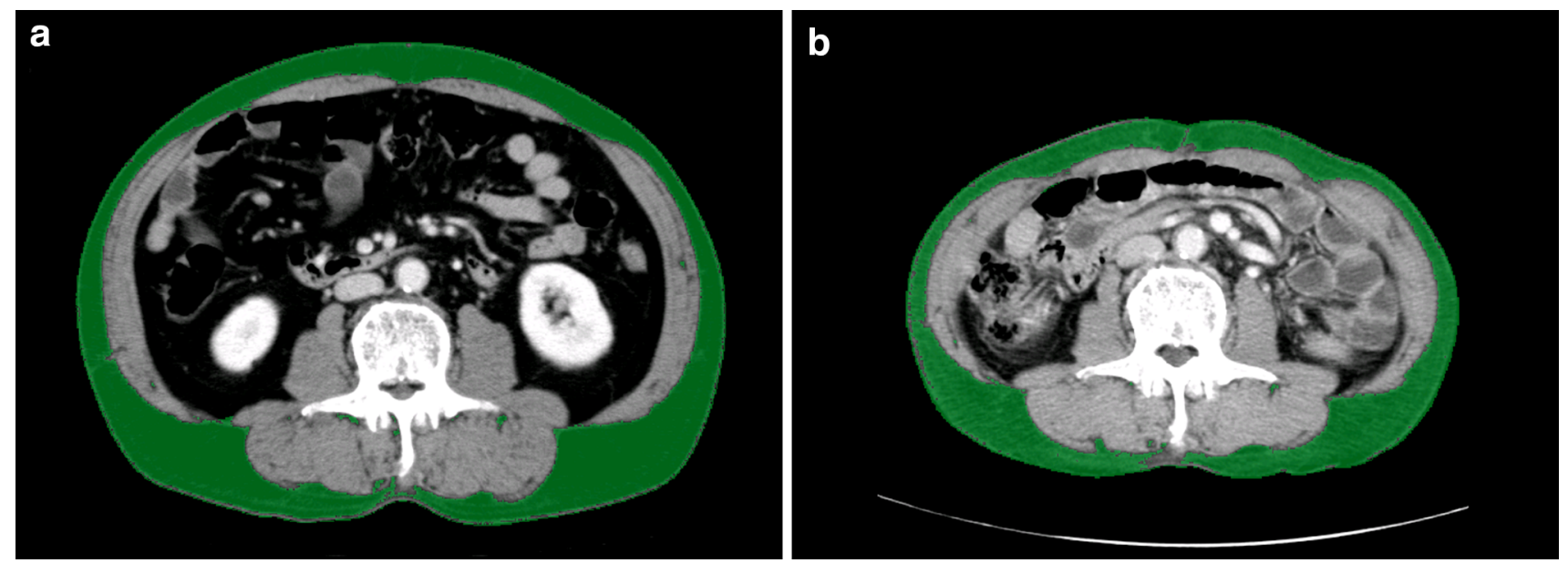

Fig. 2 Typical transverse CT images at L3 show postoperative changes in subcutaneous and intramuscular adipose tissue (green). The preoperative subcutaneous and intramuscular adipose tissue area of $135 \mathrm{~cm}^{2}$ (a) decreased to $89 \mathrm{~cm}^{2}$ at 1 year after surgery (b)

The preoperative mean BMI of all patients was $22.6 \pm 3.25 \mathrm{~kg} / \mathrm{m}^{2}$. Nine patients had comorbid DM and none received steroid therapy. Ninety-two patients underwent D2 lymphadenectomy, with combined splenectomy and distal pancreatectomy performed in 16 and 2 patients, respectively. No patient underwent lower mediastinal dissection for esophageal invasion. Postoperative complications were observed in 22 patients, involving anastomotic leakage in 3, pancreatic fistula in 5, intraabdominal abscess in 7 , ileus in 1 , wound dehiscence in 4 , and pneumonia in 2. Based on the Clavien-Dindo classification [17], these complications were categorized as grade II, III, and IV in 14, 7, and 1 patients, respectively. Fifty-two patients had pathological stage II/III disease, and of these, 38 tolerated adjuvant S-1 therapy for 6 months or more after surgery.
Postoperative changes in skeletal muscle and adipose tissue

Figure 1 shows typical transverse CT images at L3 featuring postoperative changes in skeletal muscle. The preoperative skeletal muscle area of $143 \mathrm{~cm}^{2}$ (Fig. 1a) decreased to $122 \mathrm{~cm}^{2}$ at 1 year after surgery (Fig. 1b); the preoperative SMI of $58.6 \mathrm{~cm}^{2} / \mathrm{m}^{2}$ (Fig. 1a) declined to $50.0 \mathrm{~cm}^{2} / \mathrm{m}^{2}$ (Fig. 1b). Similarly, Figs. 2 and 3 demonstrate typical transverse CT images at L3 showing postoperative changes, in subcutaneous plus intramuscular adipose tissue (Fig. 2) and in visceral adipose tissue (Fig. 3). The preoperative total adipose tissue area, which is the sum of subcutaneous, intramuscular, and visceral adipose tissues, decreased from 296 to $105 \mathrm{~cm}^{2}$ at 1 year after surgery, and the preoperative ATI of $122 \mathrm{~cm}^{2} / \mathrm{m}^{2}$ 

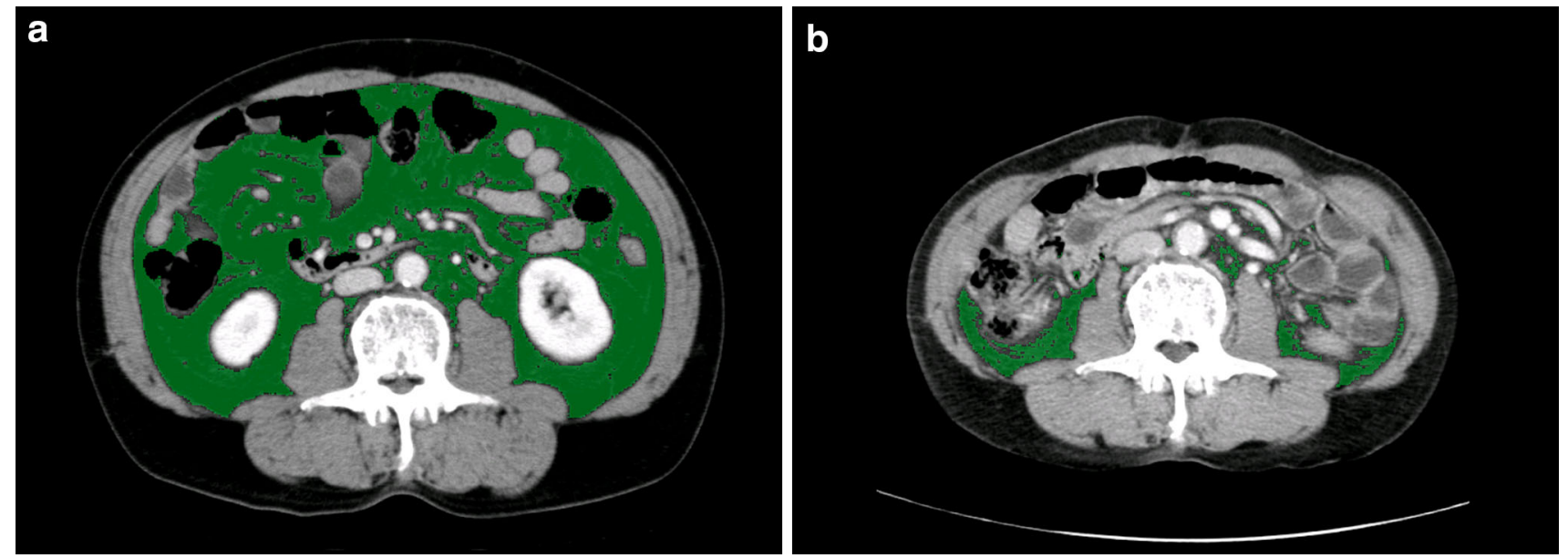

Fig. 3 Typical transverse CT images at L3 show postoperative changes in visceral adipose tissue (green). The preoperative visceral adipose tissue area of $161 \mathrm{~cm}^{2}$ (a) decreased to $16 \mathrm{~cm}^{2}$ at 1 year after surgery (b)

Table 2 Changes in body composition of patients undergoing total gastrectomy (TG) for gastric cancer $(n=102)$

\begin{tabular}{cccl}
\hline & Preoperative & $\begin{array}{l}1 \text { year after } \\
\text { TG }\end{array}$ & $\begin{array}{l}\text { Percent } \\
\text { decrease }\end{array}$ \\
\hline $\begin{array}{c}\text { Body mass index (BMI) } \\
\left(\mathrm{kg} / \mathrm{m}^{2}\right)\end{array}$ & $22.6 \pm 3.25$ & $19.1 \pm 2.43$ & $14.7 \pm 8.37$ \\
$\begin{array}{c}\text { Lumbar skeletal muscle } \\
\text { index (SMI) }\left(\mathrm{cm}^{2} / \mathrm{m}^{2}\right)\end{array}$ & $46.6 \pm 7.84$ & $43.6 \pm 6.92$ & $6.20 \pm 6.80$ \\
$\begin{array}{c}\text { Lumbar adipose tissue } \\
\text { index (ATI) }\left(\mathrm{cm}^{2} / \mathrm{m}^{2}\right)\end{array}$ & $76.4 \pm 36.4$ & $21.4 \pm 18.9$ & $65.8 \pm 36.1$ \\
\hline
\end{tabular}

decreased to $43.1 \mathrm{~cm}^{2} / \mathrm{m}^{2}$. Postoperative changes in body composition are detailed in Table 2. At 1 year after surgery, mean BMI $\left(\mathrm{kg} / \mathrm{m}^{2}\right)$ decreased from 22.6 to 19.1 , SMI $\left(\mathrm{cm}^{2} / \mathrm{m}^{2}\right)$ from 46.6 to 43.6 , and ATI $\left(\mathrm{cm}^{2} / \mathrm{m}^{2}\right)$ from 76.4 to 21.4, which corresponded to reductions of the preoperative values of $14.7 \pm 8.37 \%, 6.20 \pm 6.80 \%$, and $65.8 \pm$ $36.1 \%$, respectively.

\section{Risk factors for significant postoperative loss of skeletal} muscle

Twenty-six patients $(25.5 \%)$ showed a significant loss of skeletal muscle of more than $10 \%$ at 1 year after TG. Table 3 summarizes the results of univariate and multivariate analyses of various clinicopathological risk factors for a significant loss of skeletal muscle, including age, sex, presence of DM, postoperative complications according to the Clavien-Dindo classification, pathological stage, compliance with adjuvant chemotherapy (none or $<6$ months versus $\geq 6$ months), and preoperative SMI and ATI. Among these, adjuvant chemotherapy lasting for $\geq 6$ months (hazard ratio, 26.61; $95 \%$ confidence interval, 3.487-203.1) was identified as the single independent risk factor for a significant loss of skeletal muscle after TG. In addition, we compared the change of body composition after TG between patients who received adjuvant S-1 chemotherapy ( $\geq 6$ months) and those who did not (Table 4). There was no significant difference in terms of decreased body weight or ATI, whereas SMI decreased significantly in patients receiving adjuvant chemotherapy $(P<0.001)$.

\section{Discussion}

We conducted specific quantification of skeletal muscle mass by $\mathrm{CT}$ image analysis in patients undergoing TG. Using this approach, we demonstrated the postoperative changes in skeletal muscle mass and adipose tissue and identified the clinical factors contributing to a significant loss of skeletal muscle mass after TG. CT scan is the gold standard for quantifying skeletal muscle mass [22], and Mourtzakis et al. [18] have shown that the CT cross sectional area at L3 is strongly related to appendicular skeletal mass, a common index of sarcopenia as measured by dual-energy X-ray densitometry. CT cross-sectional area at L3 single slice was employed in many studies as a reliable method to evaluate body composition $[7,10,23]$.

In our study, mean SMI $\left(\mathrm{cm}^{2} / \mathrm{m}^{2}\right)$ decreased from 46.6 to 43.6 by 1 year after surgery and ATI $\left(\mathrm{cm}^{2} / \mathrm{m}^{2}\right)$ decreased from 76.4 to 21.4 ; these declines corresponded to $6.2 \%$ and $65.8 \%$ reductions of the preoperative values, respectively (Table 2). The general extent to which skeletal muscle mass decreases after gastrectomy remains unclear because few body composition studies have been conducted, and no research before our own has used CT image analysis to evaluate changes in skeletal muscle mass 
Table 3 Univariate and multivariate analyses of clinical risk factors for a significant loss of skeletal muscle after TG
$T G$ total gastrectomy, SMI skeletal muscle index, ATI adipose tissue index, $H R$ hazard ratio, $C I$ confidence interval

\begin{tabular}{|c|c|c|c|c|c|c|}
\hline \multirow[t]{2}{*}{ Characteristics } & \multicolumn{3}{|c|}{ Univariate analysis } & \multicolumn{3}{|c|}{ Multivariate analysis } \\
\hline & $\begin{array}{l}\text { No. of } \\
\text { patients }\end{array}$ & $\begin{array}{l}\text { No. of patients } \\
\text { having loss of } \\
\text { skeletal muscle } \\
>10 \%\end{array}$ & $P$ value & HR & $95 \% \mathrm{CI}$ & $P$ value \\
\hline \multicolumn{7}{|l|}{ Age (years) } \\
\hline$<65$ & 44 & 12 & 0.7191 & 1 & $0.194-2.462$ & 0.5694 \\
\hline$\geq 65$ & 58 & 14 & & 0.692 & & \\
\hline \multicolumn{7}{|l|}{ Sex } \\
\hline Male & 71 & 18 & 0.9614 & 1 & $0.207-5.991$ & 0.9014 \\
\hline Female & 31 & 8 & & 1.112 & & \\
\hline \multicolumn{7}{|l|}{ Diabetes mellitus } \\
\hline Present & 9 & 4 & 0.1839 & 1 & $0.019-1.086$ & 0.0601 \\
\hline Absent & 93 & 22 & & 0.143 & & \\
\hline \multicolumn{7}{|c|}{ Postoperative complications according to the Clavien-Dindo classification } \\
\hline Grade $\leq$ II & 94 & 24 & 0.9736 & 1 & $0.052-6.291$ & 0.6469 \\
\hline Grade $\geq$ III & 8 & 2 & & 0.571 & & \\
\hline \multicolumn{7}{|l|}{ Pathological stage } \\
\hline I & 50 & 3 & 0.0001 & 1 & $0.178-11.14$ & 0.7457 \\
\hline II/III & 52 & 23 & & 1.408 & & \\
\hline \multicolumn{7}{|l|}{ Adjuvant chemotherapy } \\
\hline None or $<6$ months & 64 & 4 & $<0.0001$ & 1 & $3.487-203.1$ & 0.0016 \\
\hline$\geq 6$ months & 38 & 22 & & 26.61 & & \\
\hline \multicolumn{7}{|c|}{ Preoperative SMI $\left(\mathrm{cm}^{2} / \mathrm{m}^{2}\right)$} \\
\hline$<45$ & 46 & 10 & 0.4319 & 1 & $0.382-11.39$ & 0.3965 \\
\hline$\geq 45$ & 56 & 16 & & 2.084 & & \\
\hline \multicolumn{7}{|c|}{ Preoperative ATI $\left(\mathrm{cm}^{2} / \mathrm{m}^{2}\right)$} \\
\hline$<75$ & 54 & 10 & 0.0901 & 1 & $0.761-11.21$ & 0.1182 \\
\hline$\geq 75$ & 48 & 16 & & 2.921 & & \\
\hline
\end{tabular}

Table 4 Percent decrease in body mass components after TG: effect of adjuvant chemotherapy of $\geq 6$ months

\begin{tabular}{lllc}
\hline $\begin{array}{l}\text { Body mass } \\
\text { components } \\
(\% \text { decrease after TG) }\end{array}$ & $\begin{array}{l}\text { Adjuvant chemotherapy } \\
\text { of } \geq 6 \text { months }\end{array}$ & $P$ value \\
\cline { 2 - 3 } & $\begin{array}{l}\text { Present } \\
(n=38)\end{array}$ & $\begin{array}{l}\text { Absent } \\
(n=64)\end{array}$ & \\
\hline Body weight & $15.3 \pm 8.66$ & $14.4 \pm 8.25$ & 0.5838 \\
SMI & $10.2 \pm 6.46$ & $3.83 \pm 5.84$ & $<0.001$ \\
ATI & $65.3 \pm 38.1$ & $66.1 \pm 35.1$ & 0.9324 \\
\hline
\end{tabular}

following gastrectomy. In this study, the postoperative changes in body composition after TG consisted mainly of the depletion of fat, as seen in previous studies [13-15, 24]. In fat tissue, a reduction of $56.1 \pm 36.4 \%$ in subcutaneous plus intramuscular adipose tissue and a reduction of $77.4 \pm 39.0 \%$ in visceral adipose tissue were observed in this study (data not shown). Previous CT image analyses reported decreases in subcutaneous adipose tissue and visceral adipose tissue of approximately $20-40 \%$ and
$50-60 \%$, respectively $[25,26]$. These findings suggest that the mass of visceral adipose tissue decreases more than that of subcutaneous plus intramuscular adipose tissue after TG. It has been speculated that the decrease in visceral adipose tissue is caused predominantly by the withdrawal of hypothetical gastric hormonal factors, which could increase fat mobilization or inhibit fat deposition within the visceral cavity [25].

Twenty-six patients $(25.5 \%)$ showed a significant loss of skeletal muscle of more than $10 \%$ at 1 year after TG. Although no other studies have evaluated changes in skeletal muscle mass following gastrectomy using CT image analysis, one study using multifrequency bioelectrical impedance analysis reported an $8 \%$ loss of body protein at 6 months after TG [15]. In addition, among critically ill patients admitted to the intensive care unit, $>10 \%$ loss in rectus femoris cross-sectional area was considered as clinically relevant muscle wasting [27]. Therefore, we defined a significant loss of skeletal muscle mass as a decrease in L3 skeletal muscle area of at least $10 \%$ of the preoperative value. 
Adjuvant chemotherapy with S-1, an oral 5-fluorouracil (5-FU) agent, for $\geq 6$ months was identified as the single independent risk factor for a significant loss of skeletal muscle in the multivariate analysis, whereas sex, age, presence of DM, postoperative complications, pathological stage, and preoperative SMI and ATI were not associated with a significant loss of skeletal muscle (Table 3 ). When comparing body composition at 1 year after TG between patients who had received adjuvant S-1 chemotherapy for $\geq 6$ months with those who did not (Table 4), there were no significant differences in body weight and ATI decreases, whereas SMI decreased significantly in patients receiving adjuvant $\mathrm{S}-1$ chemotherapy $(P<0.001)$. This finding could suggest that the amount of oral intake had less influence on the loss of skeletal muscle than adjuvant chemotherapy. In addition, Awad et al. [23] demonstrated a significant association of preoperative 5-FU-based chemotherapy with reductions in fat-free mass of as much as $6 \%$ in patients with esophagogastric cancer, using the method employed in this study of analyzing transverse CT images at the third lumbar vertebral level. These combined results suggest that 5-FU might affect the loss of skeletal muscle, although the precise mechanism is unknown. Another anticancer agent, doxorubicin, has recently been shown to cause a catabolic response in skeletal muscle through oxidative stress by elevating the serum levels of inflammatory cytokines, especially tumor necrosis factor (TNF), resulting in a loss of skeletal muscle mass leading to weakness and fatigue [28]. One study reported delayed skeletal muscle dysfunction in survivors of childhood acute lymphoblastic leukemia, in which repeated administration of combination chemotherapy drugs (e.g., vincristine, glucocorticoids, doxorubicin, methotrexate, asparaginase) was strongly implicated [29]. These findings suggest that chemotherapy could affect skeletal muscle loss.

On the other hand, gastrointestinal toxicities such as nausea and vomiting are frequently observed in patients receiving chemotherapy after gastrectomy [30-32]. They could cause appetite loss and decreased physical activity, and a lifestyle with lesser physical activity could potentially contribute to the loss of skeletal muscle mass. In this context, Abdiev et al. [33] raised the possibility, in patients with early gastric cancer, that laparoscopic distal gastrectomy may be beneficial in maintaining muscle mass because of an early recovery to preoperative physical activity. However, it remains uncertain whether the laparoscopic approach could prevent skeletal muscle loss even in patients receiving postoperative chemotherapy after TG.

In this study, 38 of $52(73.1 \%)$ patients with pathological stage II/III disease tolerated adjuvant S-1 therapy for $\geq 6$ months after surgery. The Adjuvant Chemotherapy Trial of S-1 for Gastric Cancer (ACTS-GC) [34] reported a similar compliance $(77.9 \%)$ with $S-1$ therapy for $\geq 6$ months, suggesting that our patients were not exceptional in this regard.

With respect to the appropriate duration of adjuvant chemotherapy with S-1, the Japan Clinical Oncology Group (JCOG) has launched a phase III trial comparing 6 versus 12 months S-1 administration in stage II gastric cancer patients [35]. A shortened period of S-1 might help early recovery of physical activity through diminishing skeletal muscle loss.

This study showed that TG caused significant postoperative changes in body composition and particularly pronounced reductions in skeletal muscle mass in patients receiving extended adjuvant chemotherapy. Marked decreases in skeletal muscle mass have been associated with poor functional status and high mortality in cancer patients, including those with gastric cancer [36, 37]. Preventing the loss of skeletal muscle mass after TG may lead to improved outcomes and better quality of life. In our patients, skeletal muscle loss had no impact on survival (data not shown). Skeletal muscle depletion in relapsed patients such as those with cancer cachexia [37] might have a completely different meaning as a prognostic factor from that caused by chemotherapy in nonrelapsed patients.

Although no nutritional interventions have yet been proven effective for preventing the loss of skeletal muscle after TG, perioperative enteral nutrition enriched with eicosapentaenoic acid (EPA) was shown to preserve lean body mass in patients undergoing esophageal cancer surgery [38]. A phase III trial is currently ongoing to evaluate the effects of perioperative nutrition enriched with EPA on body weight and lean body mass after TG for T2-T4a gastric cancer [39]. Another promising approach demonstrated that short-term administration of ghrelin maintained lean body mass at 14 days after TG [40]. An oral ghrelin mimetic over 12 months significantly increased fat-free mass in healthy older adults [41]. These results suggest that ghrelin might become a potential candidate for preventing skeletal muscle loss after TG.

Although to the best of our knowledge this is the first study examining skeletal muscle loss after TG and its exacerbation by extended adjuvant chemotherapy, the retrospective nature of this study performed in a single institution and the relatively small size of the studied population warrant further studies.

In conclusion, skeletal muscle loss was exacerbated by extended adjuvant chemotherapy after TG. Appropriate nutritional intervention should be identified to maintain skeletal muscle mass and achieve improved outcomes.

Conflict of interest The authors have no conflicts of interest with regard to this manuscript. 


\section{References}

1. Baumgartner RN, Koehler KM, Gallagher D, Romero L, Heymsfield SB, Ross RR, et al. Epidemiology of sarcopenia among the elderly in New Mexico. Am J Epidemiol. 1998;147:755-63.

2. Lang T, Streeper T, Cawthon P, Baldwin K, Taaffe DR, Harris TB. Sarcopenia: etiology, clinical consequences, intervention, and assessment. Osteoporos Int. 2010;21:543-59.

3. Cosquéric G, Sebag A, Ducolombier C, Thomas C, Piette F, Weill-Engerer S. Sarcopenia is predictive of nosocomial infection in care of the elderly. Br J Nutr. 2006;96:895-901.

4. Englesbe MJ, Patel SP, He K, Lynch RJ, Schaubel DE, Harbaugh C, et al. Sarcopenia and mortality after liver transplantation. J Am Coll Surg. 2010;211:271-8.

5. Lee JS, He K, Harbaugh CM, Schaubel DE, Sonnenday CJ, Wang $\mathrm{SC}$, et al. Frailty, core muscle size, and mortality in patients undergoing open abdominal aortic aneurysm repair. J Vasc Surg. 2011;53:912-7.

6. Englesbe MJ, Lee JS, He K, Fan L, Schaubel DE, Sheetz KH, et al. Analytic morphomics, core muscle size, and surgical outcomes. Ann Surg. 2012;256:255-61.

7. Lieffers JR, Bathe OF, Fassbender K, Winget M, Baracos VE. Sarcopenia is associated with postoperative infection and delayed recovery from colorectal cancer resection surgery. $\mathrm{Br} \mathrm{J}$ Cancer. 2012;107:931-6.

8. Pichard C, Kyle UG, Morabia A, Perrier A, Vermeulen B, Unger P. Nutritional assessment: lean body mass depletion at hospital admission is associated with an increased length of stay. Am J Clin Nutr. 2004;79:613-8.

9. Metter EJ, Talbot LA, Schrager M, Conwit R. Skeletal muscle strength as a predictor of all-cause mortality in healthy men. Am J Clin Nutr. 2004;79:613-8.

10. Tan BH, Birdsell LA, Martin L, Baracos VE, Fearon KC. Sarcopenia in an overweight or obese patient is an adverse prognostic factor in pancreatic cancer. Clin Cancer Res. 2009;15: 6973-9.

11. Kimyagarov S, Klid R, Fleissig Y, Kopel B, Arad M, Adunsky A. Skeletal muscle mass abnormalities are associated with survival rates of institutionalized elderly nursing home residents. J Nutr Health Aging. 2012;16:432-6.

12. Montano-Loza AJ, Meza-Junco J, Prado CM, Lieffers JR, Bara$\cos \mathrm{VE}$, Bain VG, et al. Muscle wasting is associated with mortality in patients with cirrhosis. Clin Gastroenterol Hepatol. 2012;10:166-73.

13. Miholic J, Meyer HJ, Müller MJ, Weimann A, Pichlmayr R. Nutritional consequences of total gastrectomy: the relationship between mode of reconstruction, postprandial symptoms, and body composition. Surgery (St. Louis). 1990;108:488-94.

14. Liedman B, Andersson H, Bosaeus I, Hugosson I, Lundell L. Changes in body composition after gastrectomy: results of a controlled, prospective clinical trial. World J Surg. 1997;21: 416-21.

15. Kiyama T, Mizutani T, Okuda T, Fujita I, Tokunaga A, Tajiri T, et al. Postoperative changes in body composition after gastrectomy. J Gastrointest Surg. 2005;9:313-9.

16. Japanese Gastric Cancer Association. Japanese classification of gastric carcinoma, 3rd English edition. Gastric Cancer. 2011;14: 101-12.

17. Dindo D, Demartines N, Clavien PA. Classification of surgical complications: a new proposal with evaluation in a cohort of 6336 patients and results of a survey. Ann Surg. 2004;240: 205-13.

18. Mourtzakis M, Prado CM, Lieffers JR, Reiman T, McCargar LJ, Baracos VE. A practical and precise approach to quantification of body composition in cancer patients using computed tomography images acquired during routine care. Appl Physiol Nutr Metab. 2008;33(16):997-1006.

19. Mitsiopoulos N, Baumgartner RN, Heymsfield SB, Lyons W, Gallagher D, Ross R. Cadaver validation of skeletal muscle measurement by magnetic resonance imaging and computerized tomography. J Appl Physiol. 1998;85:115-22.

20. Kvist H, Sjöström L, Tylén U. Adipose tissue volume determinations in women by computed tomography: technical considerations. Int J Obes. 1986;10:53-67.

21. Vehmas T, Kairemo KJ, Taavitsainen MJ. Measuring visceral adipose tissue content from contrast enhanced computed tomography. Int J Obes Relat Metab Disord. 1996;20:570-3.

22. Heymsfield SB. Development of imaging methods to assess adiposity and metabolism. Int J Obes (Lond). 2008;32:76-82.

23. Awad S, Tan BH, Cui H, Bhalla A, Fearon KC, Parsons SL, et al. Marked changes in body composition following neoadjuvant chemotherapy for oesophagogastric cancer. Clin Nutr. 2012;31: 74-7.

24. Tanaka K, Miyashiro I, Yano M, Kishi K, Motoori M, Shingai T, et al. Visceral fat changes after distal gastrectomy according to type of reconstruction procedure for gastric cancer. World J Surg Oncol. 2013;11:146.

25. Yoon DY, Kim HK, Kim JA, Choi CS, Yun EJ, Chang SK, et al. Changes in the abdominal fat distribution after gastrectomy: computed tomography assessment. ANZ J Surg. 2007;77:121-5.

26. Miyato H, Kitayama J, Hidemura A, Ishigami H, Kaisaki S, Nagawa $\mathrm{H}$. Vagus nerve preservation selectively restores visceral fat volume in patients with early gastric cancer who underwent gastrectomy. J Surg Res. 2012;173:60-7.

27. Puthucheary ZA, Rawal J, McPhail M, Connolly B, Ratnayake G, Chan $\mathrm{P}$, et al. Acute skeletal muscle wasting in critical illness. JAMA. 2013;310:1591-600.

28. Gilliam LA, St. Clair DK. Chemotherapy-induced weakness and fatigue in skeletal muscle: the role of oxidative stress. Antioxid Redox Signal. 2011;15:2543-63.

29. Scheede-Bergdahl C, Jagoe RT. After the chemotherapy: potential mechanisms for chemotherapy-induced delayed skeletal muscle dysfunction in survivors of acute lymphoblastic leukaemia in childhood. Front Pharmacol. 2013;4:1-7.

30. Cunningham D, Allum WH, Stenning SP, Thompson JN, Van de Velde CJ, Nicolson M, et al. Perioperative chemotherapy versus surgery alone for resectable gastroesophageal cancer. $\mathrm{N}$ Engl $\mathrm{J}$ Med. 2006;355:11-20.

31. Ychou M, Boige V, Pignon JP, Conroy T, Bouché O, Lebreton G, et al. Perioperative chemotherapy compared with surgery alone for resectable gastroesophageal adenocarcinoma: an FNCLCC and FFCD multicenter phase III trial. J Clin Oncol. 2011;29(13): $1715-21$.

32. Fujitani K. Overview of adjuvant and neoadjuvant therapy for resectable gastric cancer in the East. Dig Surg. 2013;30:119-29.

33. Abdiev S, Kodera Y, Fujiwara M, Koike M, Nakayama G, Ohashi $\mathrm{N}$, et al. Nutritional recovery after open and laparoscopic gastrectomies. Gastric Cancer. 2011;14:144-9.

34. Sakuramoto S, Sasako M, Yamaguchi T, Kinoshita T, Fujii M, Nashimoto A, et al. Adjuvant chemotherapy for gastric cancer with S-1, an oral fluoropyrimidine. N Engl J Med. 2007;357:1810-20.

35. Yoshikawa T, Rino Y, Yukawa N, Oshima T, Tsuburaya A, Masuda M. Neoadjuvant chemotherapy for gastric cancer in Japan: a standing position by comparing with adjuvant chemotherapy. Surg Today. 2014;44:11-21.

36. Prado CM, Lieffers JR, McCargar LJ, Reiman T, Sawyer MB, Martin L, et al. Prevalence and clinical implications of sarcopenic obesity in patients with solid tumours of the respiratory and gastrointestinal tracts: a population-based study. Lancet Oncol. 2008;9:629-35. 
37. Martin L, Birdsell L, Macdonald N, Reiman T, Clandinin MT, McCargar LJ, et al. Cancer cachexia in the age of obesity: skeletal muscle depletion is a powerful prognostic factor, independent of body mass index. J Clin Oncol. 2013;31:1539-47.

38. Ryan AM, Reynolds JV, Healy L, Byrne M, Moore J, Brannelly $\mathrm{N}$, et al. Enteral nutrition enriched with eicosapentaenoic acid (EPA) preserves lean body mass following esophageal cancer surgery: results of a double-blinded randomized controlled trial. Ann Surg. 2009;249:355-63.

39. Yoshikawa T, Hiki N, Taguri M, Sano T, Nunobe S, Taniguchi H, et al. A Phase III trial to evaluate the effect of perioperative nutrition enriched with eicosapentaenoic acid on body weight loss after total gastrectomy for T2-T4a gastric cancer. Jpn J Clin Oncol. 2012;42:459-62.

40. Adachi S, Takiguchi S, Okada K, Yamamoto K, Yamasaki M, Miyata $\mathrm{H}$, et al. Effects of ghrelin administration after total gastrectomy: a prospective, randomized, placebo-controlled phase II study. Gastroenterology. 2010;138:1312-20.

41. Nass R, Pezzoli SS, Oliveri MC, Patrie JT, Harrell FE Jr, Clasey $\mathrm{JL}$, et al. Effects of an oral ghrelin mimetic on body composition and clinical outcomes in healthy older adults: a randomized trial. Ann Intern Med. 2008;149:601-11. 